\title{
1 Managing Interfaces in Large-scale Projects: The Roles of Formal 2 Governance and Partnering
}

3 Wenxin Shen, A.M.ASCE${ }^{1}$, Wenzhe Tang, A.M.ASCE ${ }^{2}$, Yunhong Wang ${ }^{3}$, Colin F. Duffield ${ }^{4}$, Felix Kin 4 Peng Hui ${ }^{5}$, Lihai Zhang ${ }^{6}$

5 Abstract coordination and integration among stakeholders in construction project delivery, especially for large-scale projects. This paper examines the role of formal governance, partnering, and the nature of the boundary

9 activities and their interactions in the interface management performance outcomes. To achieve this goal, an 10 integrated framework with consideration of the influence of formal governance, partnering, and boundary 11 activities on interface management performance and associated project outcomes was developed and the 12 framework predictions were empirically tested by using the data collected from 85 international large-scale 13 projects. The results show that formal governance is the one of dominant determinants of interface 14 management performance, which can influence the management outcomes improving partnering and 15 boundary activities. Partnering and boundary activities are also significant antecedents of interface 16 management performance, which in turn improves project outcomes of large-scale construction projects. 17 Formal governance and partnering mutually reinforce each other. Interface management performance is 18 positively corelated to project outcomes in terms of quality, cost, and schedule. The present empirical research 19 contributes to the fundamental understanding of the critical factors that govern the interface management

\footnotetext{
${ }^{1}$ Assistant Professor, Beijing Jiaotong University, School of Economics and Management, Science and Technology Building, Beijing 100044, China. Email: shwenxin@bjtu.edu.cn

2 Professor, Institute of Project Management and Construction Technology, State Key Laboratory of Hydroscience and Engineering, Tsinghua University, New Hydraulic Building, Beijing 100084, China. (Corresponding Author) E-mails: twz@mail.tsinghua.edu.cn ${ }^{3}$ Ph.D. Candidate, Tsinghua University, Institute of Project Management and Construction Technology, State Key Laboratory of Hydroscience and Engineering, New Hydraulic Building, Beijing 100084, China.

${ }^{4}$ Professor, Dept. of Infrastructure Engineering, The University of Melbourne, Victoria 3010, Australia.

5 Senior Lecturer, Dept. of Infrastructure Engineering, The University of Melbourne, Victoria 3010, Australia.

${ }^{6}$ Associate Professor, Dept. of Infrastructure Engineering, The University of Melbourne, Victoria 3010, Australia.
} 
20 performance, ultimately the project outcomes. In addition, the outcomes of this study highlighted the broad

21 managerial implications for project participants in large-scale projects.

22 Keywords: Project management; Interface management; Governance; Partnering; Boundary activities; 23 coordination.

\section{Introduction}

Recent years have seen a growing importance in studying large-scale projects in the field of construction management because of their unique characteristics and strategic values (Flyvbjerg 2014). A large-scale construction project is usually described as a project that is characterized by its physical size, long duration, massive investment, high complexity and uncertainty, a wide range of stakeholders, significant social and economic impacts, and dynamic interfaces (Floricel and Miller 2001; Li et al. 2018). Large-scale construction projects consist of distinct but interdependent activities that are handled by a range of specialized organizations

31 (e.g., subcontractors). As a result of this distribution (and sometimes fragmentation) in roles, numerous interfaces are generated (Healy 1997). Specifically, following the definition of Wren (1967), the concept of the interface in the construction industry refers to "the common boundaries between independent but 34 interacting systems, organizations, project phases, and construction elements". Obviously, interfaces abound 35 in a construction project and each of them can be a risk to the project if it is mismanaged (Shokri et al. 2016).

36 It is widely acknowledged that interface issues such as miscommunication between parties and the inability 37 of project stakeholders to work coordinately can lead to delays and require rework to achieve the specified 38 quality (Shokri et al. 2015). The dynamic, temporary, and interdisciplinary in nature of construction projects 39 makes managing these interdependent interfaces a significant challenge for project participants.

To address the challenges above, there has been an increasing interest in using interface management 41 (IM) to enhance coordination and alignment among stakeholders (Shen et al. 2018a). As a critical 42 organizational capability, interface management is described as the process of managing the boundaries 
43 between interacting systems, phases, and organizations (CII 2014). The success of large-scale projects requires

44 collaboration and a working harmony between all project stakeholders (e.g., designers, suppliers, consultants, 45 contractors, and subcontractors), which makes IM even more significant in managing the complex and 46 dynamic interfaces among these project stakeholders (Shokri et al. 2015).

Past IM studies have focused on formal governance to improve IM implementation, which is defined as a collection of formal principles, standardized procedures, and management tools to govern interfaces (Shen

49 et al. 2018; Shokri et al. 2015). The purpose of such efforts is to allow interface stakeholders to communicate 50 and coordinate in a consistent way, thereby reducing uncertainty and ambiguity. However, such formal 51 governance is often insufficient in reality as many IM activities are unpredictable and cannot be standardized 52 in advance. Under such a situation, partnering, which can be understood as a win-win relationship between 53 participants, has been considered as a complementary and even more effective way to reduce interface issues 54 since it can provide the possibility of achieving a high degree of common goal and integration among organizations (Bresnen and Marshall 2000). By developing a long-term commitment and win-win relationship 56 among project stakeholders, partnering drives them to cooperatively work as a team disregarding 57 organizational boundaries (Tang et al. 2006).

Although researchers have suggested the significant roles of formal governance and partnering in project

59 management (Ahola et al. 2014), they have paid little attention to how these two mechanisms collectively 60 influence IM performance, which refers to efficiency and effectiveness of interface task accomplishment, and 61 the accuracy of information exchange (CII, 2014). In addition, in the context of large-scale construction 62 projects, it remains unexplored that how the IM performance influences overall project outcomes including 63 schedules, cost, and quality. Thus, this research aims to examine the effects of formal governance and 64 partnering on IM performance, thereby providing the mechanism for improving project outcomes of large- 

scale construction projects. An in-depth understanding of the key factors for managing interfaces is important 66 since it can provide the basis for choosing effective approaches to efficiently enhance the flows of information 67 and resources use.

\section{Theoretical Background and Hypotheses}

A theoretical model is proposed to investigate the relationships among formal governance, partnering, boundary activities, IM performance, and project outcomes in large-scale projects, as displayed in Fig. 1. The 71 detailed explanations of the research hypotheses are elaborated in this section.

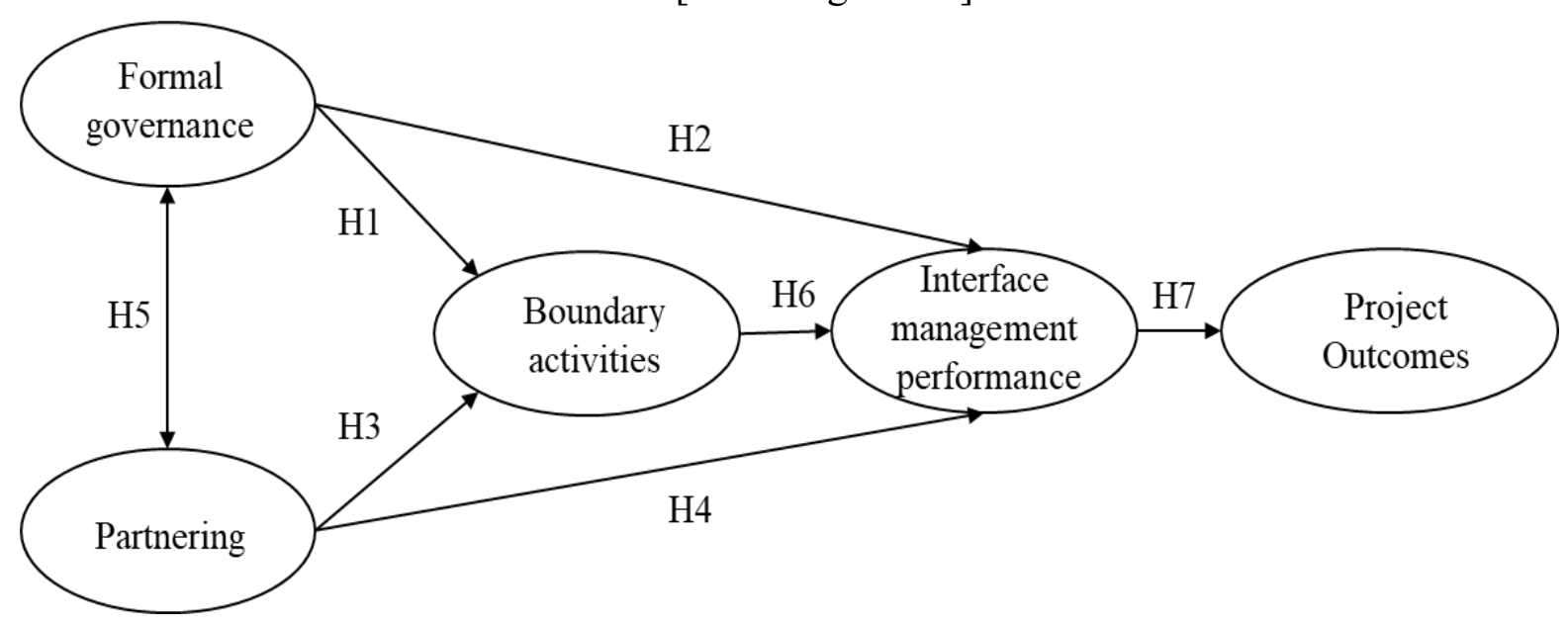

Fig. 1. Conceptual interface management framework

\section{The Role of Formal Governance in IM}

Formal governance in this study is defined as "a set of formal principles, structures, and processes for the undertaking and management of projects" (Crawford and Cooke-Davies 2009). Broadly speaking, formal governance has been viewed in two ways in the literature. One considered it as "external to any specific project" 79 and focuses on specifying standards and regulations, which can be generalized to most individual projects to 80 comply with (Ahola et al. 2014). Another view is that it is "internal to a specific project" - focuses more on 81 inter-organizational relationships (Ahola et al. 2014; PMI 2017). Instead of standardization, this view assumes 
that every project is unique, which needs to be governed in a tailored and specific manner with an open view

83 (Artto and Kujala 2008). Fundamentally, formal governance aims to balance the interests and responsibilities

84 of different stakeholders through providing a framework for project-wide managerial actions (Biesenthal and

85 Wilden 2014). Formal governance specifically employs principles for aligning goals, directing and 86 controlling the organization, and specifying stakeholders' responsibilities and rights (Müller 2009). It aims to 87 develop a shared set of procedures and contractual arrangements for all project stakeholders to follow (Ruuska et al. 2009). Formal governance of large-scale construction projects involves the development of a set of principles, responsibilities, processes, and structures (Müller et al. 2016). In construction, formal governance

pertaining to IM encompasses work breakdown structure, contractual control, standard IM procedures and 91 rules, and particular organizational structure (e.g., position) (CII 2014; Ahn et al. 2016; Shokri et al. 2016; Lin 2013). Despite the significance of managing dynamic interfaces in large-scale construction projects, it is very challenging for project managers to complete interfacing tasks because it requires strong coordinating skills to cope with various project stakeholders with different professions and interests (CII, 2014). Because IM is a relatively new management approach to most project practitioners (Chen et al. 2008), their understanding and practice of IM vary, which may affect the effectiveness of IM implementation (Ahn et al. 2016). The establishment of specified standards, routines, and regulations of IM can facilitate project participants to reach 98 a mutual understanding of their roles and responsibility on the interface tasks, which thereby reduce the 99 variances of their' behaviors across organizational boundaries (Shen et al. 2018b). As such, they are likely to 100 perceive fewer difficulties in performing boundary behaviors, which encourage them to share information and 101 collaborate with others across the organizational boundaries (Bandura 1986). It was found that the components of formal governance (e.g., standardized procedure) are the key drivers 103 for interface participants' behaviors (Shen et al. 2018a). With clear standardized procedures and rules, 
104 uncertainty and ambiguity from the inter-organizational interactions are likely to be reduced, and consequently

105 (Bidwell 2012), boundary activities such as defining and shaping the boundary, collecting and exchanging

106 information are expected to be smoother. Therefore, we proposed the following:

107 H1: Formal governance has a positive effect on boundary activities.

109 Effective formal governance can support the success of IM by providing a structure that defines the work 110 scope and directs project participants' efforts and by reinforcing their' boundary-spanning responsibilities

111 (Marrone et al. 2007). With standardized workflows and a common understanding of how to work together in 112 interdependent tasks, the collective actions at interfaces would tend to be more predictable, which will 113 encourage effective information transformation and coordination (Joslin and Müller 2016). In addition, 114 appropriate formal governance can reduce information asymmetry, which thereby reduces inter-firm 115 coordination costs and transaction costs (Williamson 1979). It was suggested that formal governance can 116 contribute to managing interfaces effectively (Pavitt and Gibb 2003). Therefore, the authors proposed the 117 following:

118 H2: Formal governance has a positive impact on IM performance.

\section{The Role of Partnering in Interface Management}

Although formal governance plays a critical role in driving interactions across organizational boundaries

122 (Biesenthal and Wilden 2014; Müller et al. 2016), many issues such as poor coordination and adversarial 123 relationships between parties still commonly arise from large-scale projects because the goals and interests of 124 project stakeholders are not aligned with each other (Tang et al. 2006). Hence, the success of large-scale 125 projects also requires another type of governance - relational governance (Cao and Lumineau 2015). 
126 Partnering, as a form of relational governance, is an emerging strategy with the attempts to generating a

127 win/win attitude among all parties and change the adversarial situation (CII 1991; Cheng and Li 2002).

Partnering encompasses critical components such as commitment, mutual goals, attitude, commitments,

129 trust, and communications and the heart of partnering is trust (Cheng and Li 2002). As trust-based partnering

130 is developed between two organizations, their boundaries will tend to be more permeable, which encouraging

131 active inter-organizational boundary activities such as communicating design issues with outsiders, obtaining

132 feedbacks, coordinating, and negotiating (Shen et al. 2017). For example, the procurement costs of materials

133 and equipment account for a large proportion of the total cost of large-scale construction projects (e.g.,

134 hydropower projects). Establishing long-term partnering relationship with major suppliers becomes a common

135 practice of many contractors because, for the contractors, this win-win solution enables stable supplies of the

136 needed resource for construction and ensures more reasonable prices, which is critical to mitigate logistical

137 uncertainties and reduce procurement cost (Azambuja et al. 2014). For the suppliers, partnering with the

138 contractors can help them access more markets.

In a climate of trust and cooperation, project stakeholders tend to voluntarily share knowledge and extra

140 information across the organizational boundary, as well as work cooperatively towards their shared goals

141 (Cheng and $\mathrm{Li}$ 2002). Building communication protocol and strengthening relationships with other

142 stakeholders are also influential to facilitate boundary-spanning activities (Du and Pan 2013; Marrone et al.

143 2007). Thus, the authors hypothesized that:

H3: Partnering has a positive effect on boundary activities.

Partnering is likely to be a pivotal factor in improving IM. In prior research, trust, openness, and 
148 improving inter-organizational IM performance (Shen et al. 2017). First, partnering is essentially a trust-based

149 relationship. Researchers have widely acknowledged that many inter-organizational cooperative behaviors

150 (e.g., teamwork and interpersonal cooperation) can be driven by the mutual trust (Jones and George 1998).

151 This kind of favorable attitude supports interactions between people and encourages members from different

152 groups to spontaneously work as a team (Jones and George 1998). Despite the existence of organizational

153 boundaries, mutual trust can promote organizational flexibility and enhance the quality of information 154 exchange (Kadefors 2004).

Second, communication has been recognized as an essential factor in successfully managing interfaces in construction projects (Chen et al. 2008; CII, 2014). Almost all activities in managing interfaces (including task-related interactions and social interactions) require communication at different levels. Thus, the authors proposed that:

H4: Partnering has a positive effect on IM performance.

Partnering and relational governance shared the core elements (e.g., shared vision, trust, cooperation, and 162 long-term commitments) (Cao and Lumineau 2015). The understanding of how relational and contractual 163 governance interplay has remained inconsistent and conditional in the literature (Zheng et al. 2008). Some 164 scholars claim the relationship between them is complementary (Benítez-Ávila et al. 2018; Ryall and Sampson 2009; Li et al. 2010). Other researchers, however, assert that relational governance and contractual governance substitute each other (Lui and Ngo 2004). According to a meta-analysis of contractual-relational governance relationships across 149 empirical research, more extant literature supports that they complement each other (Cao and Lumineau 2015). 
contractual governance and relational governance can enhance the quality of governance system as they can

171 overcome the shortfalls of one another. For example, relational governance can add more flexibility to the

172 projects that contracts cannot provide (Floricel and Miller 2001). However, in addition to complementary and

173 substitutive relationships, we argue that contractual governance and relational governance can also have the

174 third relationship - mutually reinforce each other (i.e., they are positively associated with each other), instead

175 of simply adding extra element to the governance system. Contracts with clearly defined duties and rights, fair

176 risk allocation, as well as the punishment for the breach of contract can increase the confidence of the

177 contracting parties in their cooperation and provide formal assurance for developing relational governance (Li

178 et al. 2010; Bresnen and Marshall 2000). Meanwhile, organizations with partnering mindsets would

179 automatically share extra critical information with each other without worrying the other party takes advantage 180 of it for opportunistic behaviors, which creates more values beyond the contracts (Tang et al. 2006). Better 181 relational governance can create and maintain the "win-win" climate among parties, which in turn facilitate 182 better execution of the contracts during the project delivery process (Cheng and Li 2002). Therefore, this 183 research assumed that:

184 H5: Formal governance and partnering are positively correlated with each other.

\section{The Role of Boundary Activities in IM}

An organization is not an island but relies on other organizations' inputs to maintain functioning, during

which it must engage in a set of activities across their organizational boundary (Du and Pan 2013). Based on boundary theories (Ancona and Caldwell 1990; Drach-Zahavy and Somech 2010) and the characteristics of construction projects, boundary activities in IM are defined as sets of actions: 1) acquiring resources, which 191 is about obtaining information and other resources outside the organization in order to complete interfacing 
tasks. For instance, contractors need to collect technical drawings or information from designers, and enquire

193 prices from potential suppliers; 2) informing, which are related to keep other external organizations or groups

194 informed of the organization or group's activities and progress. For example, as construction projects are 195 constitutive of enormous distinct activities, the interdependent relationships between the inputs and outputs 196 of these activities require designers and contractors to exchange and update technical information such as 197 technical standards and drawings with one another promptly to enable the accuracy and consistency of 198 information (Tang et al. 2006); 3) coordinating and negotiating, which refers to interactions aimed at handling 199 technical or design problems, such as communicating design issues with outsiders and obtaining feedbacks, 200 coordinating and negotiating with others. The execution of construction projects, for instance, is subject to 201 changes over time due to the uncertain and demanding environment, which requires a set of exact coordination 202 and shifts in skills or knowledge for accomplishing tasks (Faraj and Xiao 2006). It is noted that, although a 203 lot of boundary activities can lead to the improvement of IM, this research focuses on specific activities that 204 are formal and have a direct impact on IM outcomes.

Clearly, achieved desired IM performance requires a set of boundary activities performed jointly by project participants (CII 2014). Boundary activities could be an important mediator process for interface task accomplishment. Since large-scale construction projects require large teams with different professions, expertise and knowledge are implicitly dispersed among team members in different organizations, it is difficult to quickly locate and coordinate the "right" person who has the skill or knowledge when it is needed (Faraj and Xiao 2006). With the effective implementation of IM, frequent and timely cross-boundary communication creates more chances to accurately link the distributed expertise, which can engage project participants in the identification of inter-firm issues and result in efficient decision-making. 
214 essential to achieve high performance (Ancona and Caldwell 1990; Marrone et al. 2007). For instance, teams

215 undertaking extensive boundary-spanning activities were better able to manage expectations from the top

216 management, obtain outside information and resource, and buffer external pressures (Ancona and Caldwell

217 1990). The more adequate boundary activities, the more they understand each other's needs and behavior

218 patterns, the more likely to prevent potential interface problems (Shen et al. 2018a).

219 Thus, we proposed that:

H6: Boundary activities have a positive effect on IM performance.

As explained above, formal governance and partnering are hypothesized to have impacts on boundary activities, which can help to access critical resources to accomplish interface tasks (i.e., H1 and H3). Formal governance and partnering can also improve IM performance and it is likely that this happens through the mediating effects of boundary activities (facilitating inter-organizational interactions between stakeholders).

\section{The Role of Interface Management in Project Outcomes}

Empirical research has highlighted that opportunism, unclear project definitions, and external risks are the main causes of contractors' disputes and claims (Shen et al. 2017). Opportunism, which is regarded as behaviors that seek for self-interest (Williamson 1979), is found to be common in construction industry (Wood et al. 2001). For example, some owners pushed contractors by setting unrealistic timelines or unreasonable conditions in the contracts while some contractors intended to make more profits by submitting claims (Wood et al. 2001). Partnering, therefore, is critical and needed to reduce such opportunism and mitigate external risks by encouraging stakeholders to trust, and openly share information with each other in IM, thereby reducing disputes and enhancing project outcomes.

Unclear project definitions in work scope and technical specifications might also cause disputes between 
236 stakeholders as each party has different and even conflicting conceptions about the requirements and the

237 priority of task interdependencies (Gerwin 2004). These misalignments can yield incompatibility of efforts in

238 IM (Gulati et al. 2012), especially when facing unexpected external risks, which consequently lead to disputes

239 of IM and coordination failure. Ambiguous project definitions are often rooted in cognitive limitations, which

240 refer to individuals' inability to fully recognize the interdependence among tasks, roles, and groups (Simon

241 and March 1993). Given the bounded rationality, people often only focus on their own tasks and roles but

242 often underestimate the interdependence between tasks and groups and the needs for coordination (Puranam

243 et al. 2012). Through clarifying the division of works and formalizing inter-organizational activities, formal

244 governance in IM such as developing standardized procedures mitigates the impacts of individuals' cognitive

245 limitations (Gulati and Singh 1998) and avoid the potential for disputes in IM in dealing with external risks

246 arising from natural and socio-economic environments, which improve project outcomes.

247 It is suggested that successfully implementing IM can enhance project outcomes by improving mutual 248 understanding of the coordination needs and aligning the goals among stakeholders. For example, the 249 inadequate or incorrect design is a common cause of the incidence of safety issues, work backlogs, cost 250 overrun, and delays and it is mainly because that the designers and contractors did not have open 251 communication at the early stage to clarify clients' intentions and discuss constructability of the design (Tang 252 et al. 2013). Empirical studies also prove that projects that applied systematic IM have less cost overrun than 253 those without implementing IM as it can reduce unwanted design iteration and reworks, which are often 254 expensive and incur delay (CII 2014; Shokri et al. 2015).

Therefore, we proposed that:

H7: IM performance has a positive effect on project outcomes. 
As explained above, formal governance, partnering, and boundary activities are expected to directly

259 improve IM performance (i.e., H2, H4, and H6). Following the reasoning for H7, it is also likely that IM

performance acts as a mediator between these factors and project outcomes. In other words, formal governance,

261 partnering, and boundary activities can all indirectly impact project outcomes through the mediating effects

262 of IM performance (such as facilitating interface tasks).

\section{Empirical Study Methodology}

\section{Data Collection}

As contractors are responsible to manage information and various resources from other stakeholders for project delivery, they are one of the main entities to implement IM. Therefore, the data collection of this research is mainly based on the perspective of contractors. Specifically, we choose seven Chinese companies ranked as the ENR (Engineering News Record) top 100 contractors in 2019 (ENR 2019). All of these selected contractors have rich experience in delivering large-scale projects (e.g., hydropower projects and railway projects) in the world.

Questionnaire surveys and interviews are employed in this study. The questionnaire survey involved 200 managers whose job responsibilities include inter-organizational coordination or interface management. To ensure a consistent understanding of the concept of IM, the definition of contractor's interface management is provided at the beginning of questionnaire: a process in which the contractor and its interfacing parties jointly create norms, procedures, and structures for managing their common boundaries (i.e., interdependent tasks and working relationships) through communication and coordination, in order to yield mutually satisfactory project outcomes. The questionnaire encompasses two sections. The first one is the informants' personal information (such as positions and working experience) and general information (e.g., project duration, and project type) of one large-scale project that the informants had worked on. The second component of the 
questionnaire is the items in the conceptual framework (as detailed in the following section). To mitigate social desirability biases of the respondents, additional procedures were used by the researchers (Podsakoff et al. 2003): (1) guaranteeing the confidentiality of all individual response; (2) assuring informants that there are no standard answers to the questions and encourage them to respond honestly based on their experience in reality; and (3) informing informants that the completed questionnaires will be returned to the researcher directly so that the company will not know the detailed information in the questionnaires. After questionnaires, semistructured interviews with 25 experienced managers were employed to help researchers better understand IM in practice. Each interview lasted about 45 minutes.

\section{Data Analysis Techniques}

Statistical analyses were conducted via the statistical package for social sciences (SPSS 24.0). Structural equation modelling (SEM) is performed to analyze the hypothesized relationships in this study. SEM is a statistical procedure for testing predictive and causal hypotheses (Bagozzi and Yi 1988). It has many advantages over traditional regression and correlation analyses, especially in tests of substantive and complex interrelationships. First, SEM significantly simplifies the processes of testing mediation hypotheses as it can offer more integrative and straightforward tests of multiple mediating effects (Bagozzi and Yi 1988). For instance, to test a model consists of one mediating relationship, one should test and compare at least three separate regression models by traditional regression methods; through SEM, however, only one test is needed. Additionally, SEM provides methods to correct systematic bias as it can explicitly calculate systematic error as well as random error (Fornell and Larcker 1981). Analysis of Moment Structures (AMOS 23.0) was employed in both confirmatory factor analysis and SEM analysis.

The sample size of in this research was sufficient to obtain convergent and appropriate results for SEM as recommended by Hair et al. (2009). To further augment the reliability of the analysis results, this research 
used a bootstrapping sampling method to generate bias-corrected confidence intervals of the mediation

303 relationships and estimate the significance of the mediated paths (MacKinnon et al. 2004).

\section{Measures}

305 Table 1 summarizes the measures of the constructs in the theoretical framework, as shown below.

307 Table 1. A summary of the measures.

\section{Constructs}

\section{Descriptions}

\section{Formal Governance}

1.1 Plan

1.2 Organizational structure

1.3 Procedures

\section{Partnering}

2.1 Trust

2.2 Openness

\section{Boundary Activities}

3.1 Coordinating

3.2 Acquiring resources
A pre-established plan for managing interfaces during the project lifecycle An appropriate organizational structure which is conducive to inter-organizational communication and coordination

Detailed procedures that can be followed for executing IM activities

The degree of trust between the contractors and:

- the owner

- the designers

- the subcontractors

- the consultants

- the suppliers

- the local government

The degree of openness between the contractors and:

- the owner

- the designers

- the subcontractors

- the consultants

- the suppliers

- the local government

2.3 Communication The efficiency of communication between the contractors and:

- the owner

- the designers

- the subcontractors

- the consultants

- the suppliers

- the local government

Coordinating and negotiating with other key stakeholders in the project about the interface-related issues

Acquiring resources (e.g., information, ideas, equipment) from other companies for completing interfacing tasks 
3.3 Informing Keeping other companies in the project informed of our company's activities

\section{Interface Management Performance}

4.1 Effectiveness

4.2 Efficiency

4.3 Accuracy

5. Project Outcomes

5.1 Schedule

5.2 Cost

5.3 Quality

The extent to which the project stakeholders meet the specification in IM agreements regarding the quality of the interface task outcome The degree of adherence to schedules in the IM process

The degree of the interface-related information transition being correct or precise

The project was completed on time

The project was completed without cost overrun

The project achieves its goals on quality

Formal governance. Adapted from PMI (2017) and Shokri et al. (2016), we developed three questions

to examine the degree of formal governance in the project using a five-point Likert scale (1 represents to 311 strongly disagree, 5 represents strongly agree).

Partnering. Followed prior research (Shen et al. 2017), we adopted a three-item measure to access the

level of three elements of partnering in IM, respectively -- trust, openness, and communication. As shown in

Table 1, each of these three factors consist of six sub-items, which capture the status between the contractor and the following key stakeholders in the project: 1) Contractors - owners; 2) Contractors - designers; 3) Contractors - subcontractors; 4) Contractors - consultants; 5) Contractors - suppliers; and 6) Contractors local government. These key stakeholders were selected because they have the most frequent interactions with contractors during project delivery (Tang et al. 2006). All sub-items were assessed by a scale of 1 (very low) to 5 (very high). Then, the responses of the sub-items within each factor were averaged to get factor-level data.

Boundary activities. Build upon on the identification of Ancona and Caldwell (1990) and CII (2014), boundary activities in IM in this study are measured (1 represents to strongly disagree, 5 represents strongly agree) by three types of actions as presented in Table 1 .

IM Performance. Following the definition of CII (2014), IM performance is measure by the efficiency 
325 information exchange in the projects ( $1=$ very low; 5 = very high).

\section{Results}

\section{Descriptive Statistics and Correlation}

Out of 200 hard copies of the questionnaires, a total of 168 were sent back to the researchers (response rate of $84 \%$ ). After eliminating two responses with excessive missing data, there are 166 samples for testing the model. The respondents' average working experience in the construction industry was 11.4 years. $35.1 \%$ of respondents are with less than five years, $23.0 \%$ are with 5-10 years, $17.6 \%$ with $10-15$ years, and, $24.3 \%$ with more than 15 years. The questionnaires were collected from 85 international large-scale projects, which covered a broad range of project characteristics. As for geographical locations, sample projects are located in Africa (46.00\%), Asia (36.00\%), South America (9.00\%), Europe and Oceanica (9.00\%). As for project types, sample projects include power plant projects $(67.40 \%)$, transportation projects $(15.10 \%)$, buildings and infrastructure projects $(12.80 \%)$, and mining projects $(4.70 \%)$.

Table 2 summarizes descriptive statistics and reliabilities for all constructs. To understand the relationships between constructs, Pearson correlation analysis is also employed, with the results reported in Table 2.

[Insert Table 2 here]

Table 2. Descriptive statistics for constructs.

\begin{tabular}{lcccccccccc}
\hline & Mean & S. D & Cronbach's $\alpha$ & CR & AVE & 1 & 2 & 3 & 4 & 5 \\
\hline 1. Formal governance & 3.91 & 0.72 & 0.83 & 0.89 & 0.72 & 0.85 & & & & \\
2. Partnering & 3.67 & 0.60 & 0.97 & 0.97 & 0.91 & $0.66^{* *}$ & 0.95 & & & \\
3. Boundary activities & 3.86 & 0.72 & 0.81 & 0.88 & 0.70 & $0.74^{* *}$ & $0.61^{* *}$ & 0.84 & & \\
4. IM performance & 3.81 & 0.66 & 0.82 & 0.82 & 0.60 & $0.71^{* *}$ & $0.68^{* *}$ & $0.74^{* *}$ & 0.78 & \\
5.Project outcomes & 3.86 & 0.65 & 0.75 & 0.77 & 0.53 & $0.62^{* *}$ & $0.60^{* *}$ & $0.54^{* *}$ & $0.60^{* *}$ & 0.73 \\
\hline
\end{tabular}


Note: ** means correlation is significant at the 0.01 level (two-tailed); $\mathrm{S} . \mathrm{D}=$ standard deviations; $\mathrm{CR}=$

343 composite reliability; AVE =average variance extracted; the bold values in diagonal are the square root of the

344 AVEs; non-diagonal values are latent variable correlations. As shown in Table 2, formal governance,

345 partnering, and boundary activities in large-scale projects are significantly correlated with each other, with the

346 correlation coefficients ranging from 0.61 to 0.74 (significance level at 0.01 ). Among the three factors

347 associated with IM performance, formal governance and boundary activities are highly correlated with IM

348 performance, with the correlation coefficients being 0.68 and 0.74 , respectively. These positive estimates of

349 correlation indicate that formal governance and boundary activities have strong positive relationships with IM

350 performance. Also, it is reported that all the variables have positive relationships with project outcomes.

In addition to the descriptive statistics, one-way analysis of variance (ANOVA) were undertaken to

evaluate whether there are any significant differences between the means of the constructs in different project

categories: (a) project types: power plant, building, transportation, and mining; (b) geographical locations:

Asia, South America, Africa, Europe and Oceanica. The results of ANOVA were reported in Table 3.

\section{[Insert Table 3 here]}

Table 3. Means of constructs (by project types and geographical locations).

\begin{tabular}{|c|c|c|c|c|c|c|c|c|c|c|c|}
\hline & \multirow[b]{2}{*}{ Total } & \multicolumn{4}{|c|}{ By project types } & ANOVA & \multicolumn{4}{|c|}{ By geographical locations } & ANOVA \\
\hline & & $\begin{array}{c}\text { Power } \\
(\mathrm{N}=116)\end{array}$ & $\begin{array}{c}\text { Building } \\
(\mathrm{N}=12)\end{array}$ & $\begin{array}{c}\text { Transpor } \\
\text { tation } \\
(\mathrm{N}=28)\end{array}$ & $\begin{array}{l}\text { Mining } \\
(\mathrm{N}=10)\end{array}$ & $\begin{array}{c}\text { F } \\
\text { Statistics }\end{array}$ & $\begin{array}{c}\text { Asia } \\
(\mathrm{N}=60)\end{array}$ & $\begin{array}{c}\text { South } \\
\text { America } \\
(\mathrm{N}=15)\end{array}$ & $\begin{array}{l}\text { Africa } \\
(\mathrm{N}=76)\end{array}$ & $\begin{array}{c}\text { Europe } \\
\text { and } \\
\text { Oceanica } \\
(\mathrm{N}=15)\end{array}$ & $\begin{array}{c}\mathrm{F} \\
\text { a Statistics }\end{array}$ \\
\hline $\begin{array}{l}\text { Formal } \\
\text { governance }\end{array}$ & 3.91 & 3.92 & 3.94 & 3.87 & 3.87 & 0.06 & 3.97 & 4.04 & 3.78 & 4.16 & 1.68 \\
\hline Partnering & 3.67 & 3.69 & 3.55 & 3.62 & 3.71 & 0.28 & 3.80 & 3.74 & 3.51 & 3.90 & $3.74 *$ \\
\hline $\begin{array}{l}\text { Boundary } \\
\text { activities }\end{array}$ & 3.86 & 3.87 & 3.97 & 3.80 & 3.83 & 0.16 & 3.90 & 3.89 & 3.74 & 4.29 & 2.64 \\
\hline $\begin{array}{l}\text { IM } \\
\text { performance }\end{array}$ & 3.81 & 3.83 & 3.76 & 3.70 & 3.92 & 0.40 & 3.83 & 3.79 & 3.74 & 4.14 & 1.59 \\
\hline $\begin{array}{l}\text { Project } \\
\text { outcomes }\end{array}$ & 3.86 & 3.93 & 3.50 & 3.73 & 3.77 & 2.20 & 3.84 & 3.98 & 3.78 & 4.18 & 1.82 \\
\hline
\end{tabular}

357 Note: * significant at the 0.05 level. 
In terms of project types, the ANOVA column in Table 3 displays F-test results are all insignificant,

359 suggesting that there is no significant difference between the means of four project types. In terms of

geographical locations, results show that there is no significant difference between the means of the four

geographical locations apart from partnering. Therefore, the data used in this research can represent a general

view of construction projects to a large extent.

To understand the level of partnering between contractors and other project stakeholders, the informants were asked to evaluate the level of trust, openness, and communication on a five-point Likert scale, which are the three basic elements of partnering in IM. The results are provided in Table 4.

\section{[Insert Table 4 here]}

Table 4. Level of elements of partnering (i.e., trust, openness, and communication) between contractors and other project stakeholders $(1=$ low, 5 = high $)$.

\begin{tabular}{ccccccc}
\hline & $\begin{array}{c}\text { Trust } \\
\text { (S.D.) }\end{array}$ & Rank & $\begin{array}{c}\text { Openness } \\
\text { (S.D.) }\end{array}$ & Rank & $\begin{array}{c}\text { Communication } \\
\text { (S.D.) }\end{array}$ & Rank \\
\hline Contractors-Owners & $3.88(0.82)$ & 1 & $3.69(0.88)$ & 4 & $3.59(0.92)$ & 2 \\
Contractors-Designers & $3.61(0.91)$ & 4 & $3.75(0.86)$ & 1 & $3.51(0.89)$ & 4 \\
Contractors-Consultants & $3.67(0.83)$ & 3 & $3.73(0.84)$ & 3 & $3.63(0.87)$ & 1 \\
Contractors-Suppliers & $3.70(0.80)$ & 2 & $3.74(0.78)$ & 2 & $3.58(0.83)$ & 3 \\
Contractors-Subcontractors & $3.46(0.78)$ & 6 & $3.59(0.82)$ & 5 & $3.40(0.87)$ & 5 \\
Contractors-Local government & $3.59(0.76)$ & 5 & $3.59(0.86)$ & 5 & $3.39(0.88)$ & 6 \\
\hline
\end{tabular}

As shown in the second column in Table 3, the level of trust between contractors and owners receives the highest, indicating that both parties attach importance to the establishment of trust relationship and have achieved certain results. As for the openness, the level of openness between the contractors and designers has the highest score (see the fourth column in Table 4), followed by consultants and suppliers, indicating that these stakeholders can share the needed information with contractors without hiding key information. Regarding the communication, the last column in Table 4 shows that the communication efficiency between 
the contractor and other stakeholders is relatively low (mean value is 3.52), indicating that there are still rooms for improvement. Among the key stakeholders, communication between contractors and consultants scored highest, reflecting frequent and close contacts with contractors, and timely exchange of information. It is noted that the score of communication between contractors and designers is lower than the average level. According to the interviewees reported, language and time difference, as well as the differences between Chinese and international technical standards were the important reasons for low communication efficiency.

\section{Measurement Model Evaluation}

\section{Internal Consistency}

Cronbach alphas were derived to examine the internal consistency of indicators. Good internal consistency is achieved when the value of Cronbach's alphas is greater than 0.7 (Sharma 1996). With the help of Statistical Package for Social Sciences (SPSS 21.0), Cronbach's alphas of all constructs were calculated (see Table 2). Cronbach's alphas of all constructs range from 0.81 to 0.97 , indicating that good internal consistency of the constructs.

\section{Construct Validity}

Construct validity is used to reflect the extent to which items of a latent variable measure what they are supposed to measure (Bagozzi and Yi 1988). To test the construct validity, convergent and discriminant validity assessment of latent constructs were performed via confirmatory factor analysis (CFA) using AMOS 23. First, A CFA model was built with 4 latent variables (i.e., Formal governance, partnering, boundary activities, and IM performance) and 14 indicators (see the section of Measures). Satisfactory model fits are achieved when the goodness-of-fit(GOF) statistics meet the following criteria: $1.0 \leqslant$ chi square/degree of freedom $\left(\mathrm{X}^{2} / \mathrm{DF}\right) \leqslant 3.0$, root-mean-square error of approximation index (RMSEA) $\leqslant 0.08$, goodness-of-fit index $(\mathrm{GFI}) \geqslant 0.9$, comparative fit index (CFI) $\geqslant 0.9$, Tucker-Lewis index (TLI) $\geqslant 0.9$ (Bentler 1990). The 
397 GOF statistics imply that the CFA model fits the data well (see Table 5).

399 Table 5. Goodness-of-Fit measures of CFA and the final model.

\begin{tabular}{cccc}
\hline GOF & CFA & Final model & Threshold \\
\hline $\mathrm{X}^{2} / \mathrm{DF}$ & 2.08 & 1.64 & $1.00-3.00$ \\
GFI & 0.89 & 0.91 & 0.9 or above \\
TLI & 0.94 & 0.97 & 0.9 or above \\
CFI & 0.96 & 0.97 & 0.9 or above \\
RMSEA & 0.08 & 0.06 & 0.08 or below \\
\hline
\end{tabular}

Note: $\mathrm{GOF}=$ goodness-of-fit indexes; $\mathrm{X}^{2} / \mathrm{DF}=$ chi square/degree of freedom; GFI=goodness-of-fit index; TLI=Tucker-Lewis index; CFI =comparative fit index; and RMSEA=root-mean-square error of approximation.

Convergent validity, meaning the degree of homogeneity for a set of items of a latent construct, is assessed by factor loadings, composite reliability (CR), as well as average variance extracted (AVE). Based on the results of CFA, standardized factor loadings of all items range from 0.77 to 0.97 and more than 0.7 , which is acceptable (Hair et al. 2009). According to Fornell and Larcker (1981), the value of CR should be greater than 0.70 and the value of AVE should be 0.50 or above to support convergent validity. As reported in Table 2, the composite reliabilities range from 0.76 to 0.98 , while the AVEs range from 0.51 to 0.91 . The results above indicate that all constructs show good convergent validity.

Discriminant validity represents the extent to which "measures of two constructs are empirically distinct"

412 (Bagozzi and Yi 1988). This type of validity is determined if the square roots of AVEs of every construct are 413 greater than the inter-construct correlations (Fornell and Larcker 1981). As displayed in Table 2, all constructs 414 exhibit good discriminant validity. 
with 5000 subsamples, the structural model results are displayed in Fig. 2, and the measures of fit are summarized in Table 4 with corresponding thresholds (Bentler 1990). The GOF statistics suggest that the final 419 model fits well.

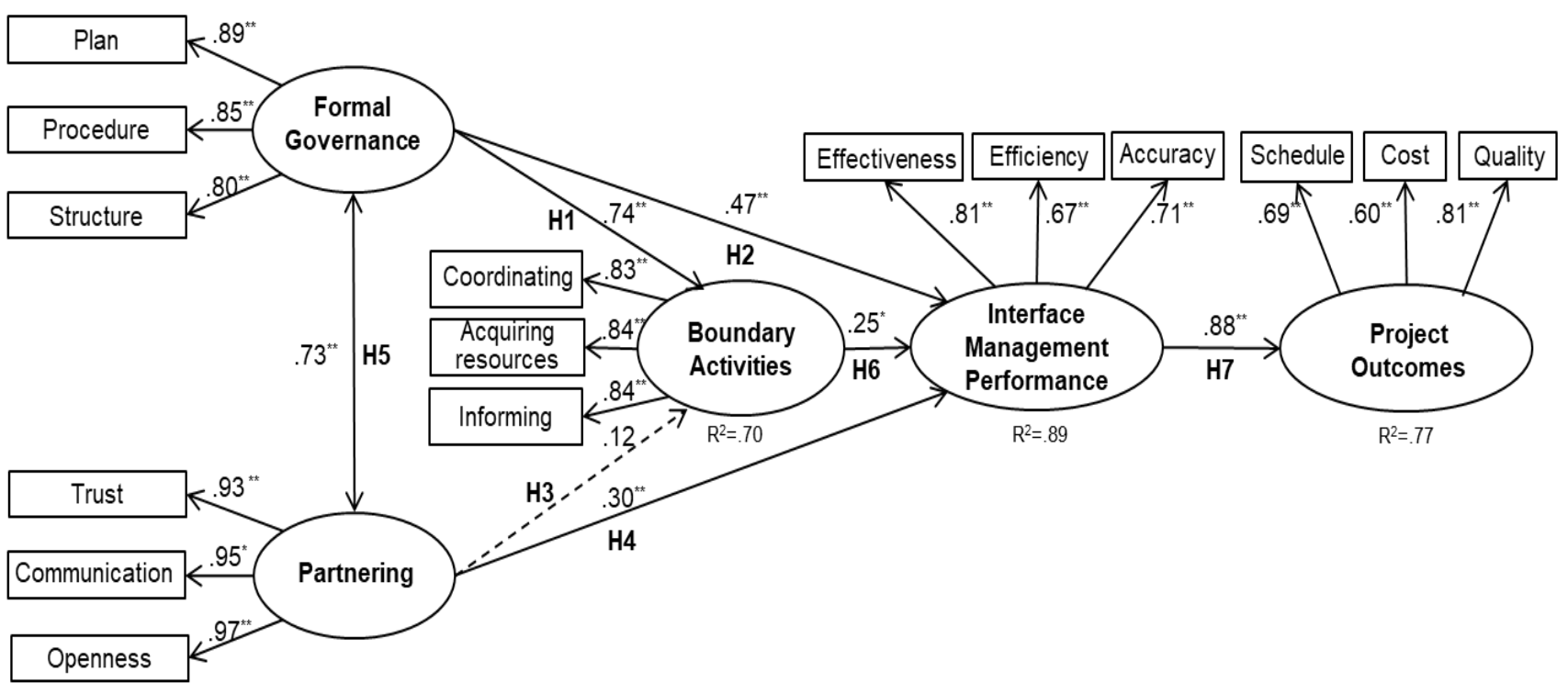

Note: $* *=$ regression coefficient is significant at the 0.01 level (two-tailed); $*=$ regression coefficient is significant at the 0.05 level (two-tailed); the insignificant path is shown as dashed lines; based on bootstrapping of 5000 subsamples.

Fig. 2. Parameter estimates for the structural model.

Direct Effect. Factor loadings are all statistically significant and error variances low. H1 that Formal governance has a positive impact on boundary activities is supported $\left(\beta=0.74, p<0.01, \mathrm{R}^{2}=0.70\right)$. There is a positive relationship between formal governance and IM performance, as proposed in $\mathrm{H} 2(\beta=0.47, p<0.01)$. Contrary to $\mathrm{H} 3$ that partnering has a positive effect on boundary activities, the relationship between these two variables failed to reach statistical significance. H4 and H6 hypnotized that partnering and boundary activities 
activities emerge as predictors of IM performance, in support of $\mathrm{H} 4(\beta=0.30, p<0.01)$ and $\mathrm{H} 6(\beta=0.25, p<$ 435 0.05), respectively. It was also found that partnering and formal governance are correlated with each other $436(\mathrm{r}=0.73, p<0.01)$, supporting H5. In support of H7, IM performance is positively associated with project outcomes $(\beta=0.88, p<0.01)$. It is estimated that three predictors in the model, namely formal governance, partnering and boundary activities, explain $89 \%$ of the variance in IM performance $\left(\mathrm{R}^{2}=0.89\right)$.

Mediation Effect. We performed mediation analysis by examining the magnitude and the significance level of two sets of mediation effects in the final model (Wang et al. 2013): 1) the mediation effects of formal governance and partnering on IM performance through boundary activities; 2) the mediation effects of formal governance and partnering on project outcomes through boundary activities and IM performance. The bootstrapping estimates are shown in Table 6, where the magnitude of mediation is calculated as the product of all the standardized path coefficients of the variables in the mediated path (Hoyle and Kenny 1999). The pvalues displayed in Table 6 demonstrate that four out of the five examined mediation effects are statistically significant. In other words, boundary activities partially mediate the relationship between formal governance and IM performance. IM performance fully mediates the relationships between formal governance, partnering, and project outcomes.

\section{[Insert Table 6 here]}

Table 6. Significance of mediated paths in the final model.

\begin{tabular}{|c|c|c|c|c|c|c|}
\hline Indirect effects & Mediated paths & $\begin{array}{c}\text { Standardized } \\
\text { estimates }\end{array}$ & $\begin{array}{c}\text { Standardized } \\
\text { errors }\end{array}$ & $\begin{array}{l}\text { Lower } \\
\text { bounds }\end{array}$ & $\begin{array}{l}\text { Upper } \\
\text { bounds }\end{array}$ & $\mathrm{p}$ \\
\hline $\mathrm{FG} \rightarrow \mathrm{IMP}$ & $\mathrm{FG} \rightarrow \mathrm{BA} \rightarrow \mathrm{IMP}$ & 0.19 & 0.09 & 0.02 & 0.28 & 0.02 \\
\hline $\mathrm{FG} \rightarrow \mathrm{PO}$ & $\mathrm{FG} \rightarrow \mathrm{BA} \rightarrow \mathrm{IMP} \rightarrow \mathrm{PO}$ & 0.58 & 0.08 & 0.27 & 0.55 & 0.00 \\
\hline $\mathrm{PA} \rightarrow \mathrm{IMP}$ & $\mathrm{PA} \rightarrow \mathrm{BA} \rightarrow \mathrm{IMP}$ & 0.03 & 0.03 & -0.01 & 0.10 & 0.13 \\
\hline $\mathrm{PA} \rightarrow \mathrm{PO}$ & $\mathrm{PA} \rightarrow \mathrm{IMP} \rightarrow \mathrm{PO}$ & 0.29 & 0.08 & 0.11 & 0.39 & 0.00 \\
\hline $\mathrm{BA} \rightarrow \mathrm{PO}$ & $\mathrm{BA} \rightarrow \mathrm{IMP} \rightarrow \mathrm{PO}$ & 0.22 & 0.10 & 0.02 & 0.29 & 0.02 \\
\hline
\end{tabular}


451 Notes: $\mathrm{FG}=$ Formal governance; $\mathrm{PA}=$ Partnering; $\mathrm{BA}=$ Boundary activities; $\mathrm{IMP}=\mathrm{IM}$ performance; $\mathrm{PO}=\mathrm{Project}$ 452 outcomes.

\section{Discussion}

Overall, an integrated framework for the effects of formal governance, partnering, and boundary activities

on IM performance in large-scale projects has been modeled (see Fig. 1) and empirically tested, with the results summarized in Table 7. The main findings of this paper are discussed below.

\section{[Insert Table 7 here]}

Table 7. Summary of the results of the final model.

\begin{tabular}{|c|c|c|c|c|}
\hline Hypotheses & $\begin{array}{c}\text { Unstandardized } \\
\text { estimates }\end{array}$ & $\begin{array}{c}\text { Standardized } \\
\text { estimates }\end{array}$ & $\mathrm{p}$ & Results \\
\hline $\begin{array}{l}\text { H1: Formal governance has a positive impact on } \\
\text { boundary activities. }\end{array}$ & 0.77 & 0.74 & $* *$ & Supported \\
\hline $\begin{array}{l}\text { H2: Formal governance has a positive impact on IM } \\
\text { performance. }\end{array}$ & 0.34 & 0.47 & $* *$ & Supported \\
\hline $\begin{array}{l}\text { H3: Partnering has a positive effect on boundary } \\
\text { activities. }\end{array}$ & 0.16 & 0.12 & 0.17 & $\begin{array}{l}\text { Not } \\
\text { Supported }\end{array}$ \\
\hline $\begin{array}{l}\text { H4: Partnering has a positive effect on IM } \\
\text { performance. }\end{array}$ & 0.27 & 0.30 & $* *$ & Supported \\
\hline $\begin{array}{l}\text { H5: Formal governance and partnering are positively } \\
\text { correlated with each other. }\end{array}$ & 0.30 & 0.73 & $* *$ & Supported \\
\hline $\begin{array}{l}\text { H6: Boundary activities have a positive effect on IM } \\
\text { performance. }\end{array}$ & 0.18 & 0.25 & $*$ & Supported \\
\hline $\begin{array}{l}\text { H7: IM performance has a positive effect on project } \\
\text { outcomes. }\end{array}$ & 0.82 & 0.88 & $* *$ & Supported \\
\hline
\end{tabular}

Notes: $* *=$ significant at the 0.01 level (two-tailed); ${ }^{*}=$ significant at the 0.05 level (two-tailed) 
First, this study empirically tests formal governance's impact on boundary activities and IM performance.

As shown in Table 7, $\mathrm{H} 1$ and $\mathrm{H} 2$ are supported, which is in line with the statements in prior literature that formalized approaches can contribute to IM practice (Shen et al. 2018a). Fig. 2 illustrates that formal governance can not only exert influence on partnering and boundary activities to improve IM performance but directly facilitate IM performance. That means, the power of formal governance in IM can be reflected in two ways: one way is encouraging formal mechanisms to promote boundary activities and enable effective information processing and coordination; another way is strengthening informal and relational mechanisms (i.e., partnering) for boundary activities. Moreover, formal governance on IM performance is much greater than the impact of partnering and boundary activities, suggesting that it is more effective for fulfilling the goals of IM. As IM has not been widely applied in the construction industry yet, many project participants may lack knowledge and experience about how to implement IM effectively. The temporary project organizations generally undergo a process of adaptation (Savelsbergh et al. 2015). In such uncertain situations, by specifying standardized IM processes and techniques, formal governance can provide project participants guidance on boundary activities and reduce human errors, which can thereby improve the efficiency of collaboration. This can be achieved by establishing pre-established plans, formalized procedures, as well as standardized information and communication systems. The specification in managing interfaces makes the interactions between stakeholders easier because project participants' activities during IM are mainly based on the codified blueprint and thereby more predictable, which will also benefit the development of trust and cohesive environments (Shen et al. 2017). The findings can also help to partly explain why many organizations usually input large amounts of resources to establish a standardized and formal governance system.

Second, in support of $\mathrm{H} 4$, this study finds that partnering has a direct impact on IM performance in largescale projects and its standardized path coefficient to IM performance is the second largest (0.303) among three antecedents. Despite the advantages of formal governance, it is impossible that a contract and procedures can anticipate every possible situation. Partnering has been viewed as an effective strategy to prevent and cope with various unexpected events arising from the dynamic and uncertainty of construction projects (Floricel and Miller 2001). However, there is no evidence to show that partnering has a significant direct impact on boundary activities. Also, according to the findings detailed in Table 6, it seems that boundary activities does 
not have a mediation effect between partnering and IM Performance. These two results could be attributed to

that the "win-win" philosophy of partnering motivates involved parties to openly share the latest information or proactively provide extra important resources, which directly enhances the efficiency and effectiveness of IM, as well as the quality of information exchange (i.e., IM performance). Consequently, in some cases, partnering does not necessarily drive boundary activities such as acquiring and confirming information from other organizations back and forth, which are officially inter-organizational interactions, especially when controlling other determinants such as formal governance. Partnering can indirectly impact IM Performance through improving formal governance.

Third, in support of H5, formal governance and partnering are positively correlated, suggesting that they can mutually reinforce each other. A project stakeholder with sound formal governance such as setting clear plans, appropriate structures, and standardized processes facilitates winning the trust of other stakeholders, and creating open communication among them, which makes the organizational boundaries more flexible and permeable (Crowley and Karim 1995). The enhanced partnering can in turn engage project participants to effectively implement the IM-related plans and procedures. The strong correlation between formal governance and partnering can explain that why the relationship between partnering and boundary activities is not significant after controlling for other predictors' effects (see Fig. 2), and partnering exerts an indirect impact on boundary activities through enhancing formal governance.

Fourth, the findings show that boundary activities are also a predictor of IM performance. Compared with the other two predictors (i.e., formal governance and partnering), its contribution towards interface management performance is relatively low (0.25), indicating that IM performance is largely driven by formal governance and partnering. In the face of the omnipresent unexpected under varying conditions in large-scale construction projects, formal governance and partnering sometimes are still insufficient to deal with unexpected events because of the inherent organizational boundaries. In such a situation, ongoing interactions (e.g., acquiring resources, coordinating and negotiating) among stakeholders at the boundaries are required. Project participants need to work with both insiders and outsiders of the organization, to obtain information and resources to achieve project goals. Our finding suggests that IM performance largely depends upon the ways people coordinately work together. 


\section{Conclusions}

\section{Findings}

In this study, a theoretical framework has been proposed to examine the interrelationships among formal

governance, partnering, boundary activities and their effects on the performance of interface management and

519 project outcomes. With the questionnaire survey and interviews in 85 international large-scale construction

projects, the framework has been empirically tested, with the results as below. First, formal governance not only is positively associated with IM performance but also exerts an indirect influence on IM performance through improving partnering and boundary activities. Second, partnering and boundary activities can positively affect IM performance. Third, IM performance has a positive effect on project outcomes. Fourth, formal governance and partnering mutually reinforce each other, and partnering exerts an indirect impact on boundary activities through enhancing formal governance.

\section{Contributions to the Body of Knowledge and Practice}

The above results have significant theoretical implications. First, this study contributes to interface management literature by advancing our understanding of how to effectively implement interface management through formal governance and partnering to achieve better project outcomes. While previous research of IM emphasized the merits of formal procedures and systems from a practical perspective (Shokri et al. 2015; Chen et al. 2008; Pavitt and Gibb 2003), this study develops a more comprehensive model to empirically investigate the impacts of formal governance and partnering on IM performance. This empirical research highlights the significance of IM in improving project outcomes. It is evident that enhancing IM can facilitate the effectiveness, efficiency, and accuracy of information flow between organizations, which can help to achieve project outcomes.

Second, although a large body of research has examined the roles of these two factors on project outcomes (e.g., Benítez-Ávila et al. 2018; Ryall and Sampson 2009), it is still not clear how they interactively contribute to improving IM in large-scale projects as IM is an emerging practice in the construction industry. The present 
study extends the discussion of and empirically tests the relationships between formal governance and 540 relational governance on boundary activities in the context of IM.

Third, different from the complementary and substitutive relationships in most literature (Zheng et al. 2008; Cao and Lumineau 2015), this research provides a more nuanced view on the relationships between formal governance approaches and informal relational approaches: they can mutually reinforce each other. Formal governance can provide assurance for developing partnering and enhanced partnering can in turn engage project participants to enhance the implementation of the plans and procedures, thereby smoothing boundary activities and improving IM performance. Fourth, this research extends boundary theories within the field of construction management. Based on the literature on boundary theories, this research elaborates on the concept of boundary activities in the context of IM, and empirically investigates its mediating roles in improving the final project outcomes.

The outcomes of this study suggest broad managerial implications for project participants in large-scale projects. First, the results of the model (see Fig. 2) highlight the importance of formal governance in promoting IM performance. This implies that institutional standards can foster collaboration and coordination among interface parties. It is suggested that contractors need to make efforts in developing an appropriate project organization structure, and optimizing inter-organizational workflows to facilitate interface tasks. Second, partnering has been proved as a significant factor to promote IM performance in large-scale projects. This indicates that measures should be taken to constantly establishing and enhancing trust, openness, and communication between stakeholders for achieving project goals in terms of schedule, cost, and quality. Third, the survey results reveal the status of partnering between contractors and other key stakeholders, which provide a sound basis to take measures to improve partnering with stakeholders.

\section{Limitations and Future Research Directions}

Several limitations have been recognized in this research. First, the theoretical model in this research is tested only by the data collected from the angle of contractors. However, IM in a large-scale project requires all stakeholders' participation. We call for future studies to test and extend the theoretical model by 
564 incorporating other views of key stakeholders in construction projects (such as clients, designers, and 565 consultants) to obtain richer insights into this topic. Second, although the sample size is 166, they were 566 collected from seven Chinese contractors of 85 international large-scale projects, which covers a broad range 567 of project characteristics regarding geographical locations and project types. This can reasonably reduce the 568 bias of selecting samples. However, it is suggested that future studies to enlarge the sample size and further 569 investigate IM in different areas and contexts.

\section{Data Availability Statement}

All data and models that support the findings of this study are available from the corresponding author upon reasonable request.

\section{Acknowledgments}

This research is supported by China Postdoctoral Science Foundation (Grant Nos. 2020M680333), the National Natural Science Foundation of China (Grant Nos. 51579135, 51379104) and Major Science and Technology Research Project of Power China (Grant Nos. DJ-ZDZX-2015-01-02, DJ-ZDZX-2015-01-07).

The authors also thank the respondents for their contributions during the survey.

\section{Conflict of Interest}

The authors declare that there is no conflict of interest.

\section{References}

Ahn, S., Shokri, S., Lee, S. Haas, and C. Haas, R. 2016. "Exploratory study on the effectiveness of interface-management practices in dealing with project complexity in large-scale engineering and construction projects." J. Manage. Eng. 04016039.

Ahola, T., Ruuska, I., Artto, and K. Kujala, J. 2014. "What is formal governance and what are its origins?." Int. J. Project Manage. 32(8), 1321-1332. 
Ancona, D.G., and Caldwell, D. 1990. "Beyond boundary spanning: Managing external dependence in product development teams." The Journal of High Technology Management Research. 1(2),119-135.

Azambuja, M., Ponticelli, S., and O'Brien, W. 2014. "Strategic procurement practices for the industrial supply chain.” J. Constr. Eng. Manage., 10.1061/(ASCE)CO.1943-7862.0000851, 06014005.

Bagozzi, R.P., and Yi, Y. 1988. "On the evaluation of structural equation models." Journal of the Academy of Marketing Science. 16 (1), 74-94.

Bandura, A. 1986. "The explanatory and predictive scope of self-efficacy theory.” J. Soc. Clin. Psychol. 4(3):359-373.

Bentler, P.M. 1990. "Comparative fit indexes in structural models.” Psychological Bulletin. 107(2), 238246.

Benítez-Ávila C., Hartmann A., Dewulf G., and Henseler J. 2018. "Interplay of relational and contractual governance in public-private partnerships: The mediating role of relational norms, trust and partners' contribution." Int. J. Proj. Manag. 36(3), 429-443.

Bidwell, M. J. 2012. "Politics and Firm Boundaries: How Organizational Structure, Group Interests, and Resources Affect Outsourcing." Organization Science, 23(6), 1622-1642.

Biesenthal, C., and Wilden, R. 2014. "Multi-level formal governance: trends and opportunities." Int. J. Proj. Manag. 32 (8), 1291-1308.

Bresnen, M., and Marshall, N. 2000. "Motivation, commitment and the use of incentives in partnerships and alliances." Constr. Manage. Econom. 18, 587-98.

Cao, Z., and Lumineau, F. 2015. "Revisiting the interplay between contractual and relational governance: A qualitative and meta-analytic investigation.” Journal of Operations Management. 33, 15-42.

Chen, Q., Reichard, G., and Beliveau, Y. 2008. "Multiperspective approach to exploring comprehensive cause factors for interface issues." J. Constr. Eng. Manag. 134(6), 432-441.

Cheng, E., and Li, H. 2002. "Construction partnering process and associated critical success factors: Quantitative investigation.” J. Manage. Eng. 184, 194-202.

Construction Industry Institute (CII), 1991. In search of Partnering Excellence. Construction Industry Development Agency. Sydney.

Construction Industry Institute (CII), 2014. Interface Management Implementation Guideline (IMIGe). IR Interface Management. The University of Texas at Austin, Austin, Texas.

Crawford, L., Cooke-Davies, T., 2009. Project Governance: The Role and Capabilities of the Executive Sponsor. Project Perspectives, vol. XXXI 66-74.

Du, W. D., and Pan, S. L. 2013. "Boundary Spanning by Design : Toward Aligning Boundary-Spanning Capacity and Strategy in IT Outsourcing." IEEE Transactions on Engineering Management, 60(1), 59-76.

ENR (Engineering News-Record). 2019. Top 250 international contractors, McGraw-Hill, New York.

Faraj, S., and Xiao, Y. 2006. "Coordination in fast-response organizations.” Management Science, 52(8), 1155-1169.

Floricel, S., and Miller, R. 2001. "Strategizing for anticipated risks and turbulence in large-scale engineering projects." International Journal of Project Management, 19, 445-455. 
Flyvbjerg, B., 2014. "What you should know about megaprojects and why: an overview". Proj. Manag. J. 45:6-19. http://dx.doi.org/10.1002/pmj.21409.

Fornell, C.G., and Larcker, D.F. 1981. "Evaluating structural equation models with unobservable variables and measurement error." J. Mark. Res. 18, 39-50.

Gerwin, D. (2004). "Coordinating new product development in strategic alliances". The Academy of Management Review, 29(2), 241-257.

Gulati, R., Wohlgezogen, F., Zhelyazkov, P., 2012. "The Two Facets of Collaboration: Cooperation and Coordination in Strategic Alliances". Acad. Manag. Ann. 6, 531-583.

Gulati, R., Singh, H. (1998). "The architecture of cooperation: Managing coordination costs and appropriation concerns in strategic alliances". Administrative Science Quarterly, 43(4), 781-814

Hair, J.F., Black, W.C., Babin, J.B., Anderson, R.E., and Tatham, R.L. 2009. Multivariate Data Analysis. 6th ed. Pearson Education Inc, Upper Saddle River, NJ.

Healy, P. 1997. "Interfaces." Project management: Getting the job done on time and in budget, Butterworth-Heinemann, Port Melbourne, Australia, 267-278.

Hoyle, R. H., and Kenny, D. A. 1999. "Statistical Power and Tests of Mediation," in Statistical Strategies for Small Sample Research, R. H. Hoyle (ed.), Newbury Park, CA: Sage Publications.

Jones, G. R., and George, J. M. 1998. "The experience and evolution of trust: Implications for cooperation and teamwork." Academy of Management Review, 23: 531-546.

Joslin, R., and Müller, R. 2016. “The relationship between formal governance and project success.” Int. J. Proj. Manag. 34(4), 613-626.

Kadefors, A. 2004. "Trust in project relationships_-Inside the black box.” Int. J. Project Manage., 22(3), $175-182$

Li, Y., Han, Y., Luo, M., Zhang, Y., 2019. “Impact of mega formal governance on project performance: Dynamic governance of the Nanning transportation hub in China". Journal of Management in Engineering, 35(3), 05019002.

Li, J.J., Poppo, L., Zhou, K.Z., 2010. "Relational mechanisms, formal contracts, and local knowledge acquisition by international subsidiaries". Strat. Manage. J. 31 (4), 349-370.

Lin, Y.C. 2013. "Construction network-based interface management system." Autom. Constr. 30, 228 241.

Lui, S.S., and Ngo, H.Y. 2004. "The role of trust and contractual safeguards on cooperation in non-equity alliances." J. Manage. 30 (4), 471-485.

MacKinnon, D. P., Lockwood, C. M., and Williams, J. 2004. "Confidence limits for the indirect effect: Distribution of the product and resampling methods". Multivariate Behavioral Research, 39: 99-128.

Marrone, J. A., Tesluk, P. E., and Carson, J. B. 2007. "A multilevel investigation of antecedents and consequences of team member boundary-spanning behavior." Academy of Management Journal, 50(6), 1423-1439.

Müller, R. 2009. Project Governance. Gower, Aldershot. 
Müller, R., Turner, J.R., Shao, J., Andersen, E.S., and Kvalnes, O. 2016. "Governance and ethics in temporary organizations: the mediating role of corporate governance.” Proj. Manag. J. 47 (6), 7-23.

Pavitt, T. C., Gibb, A. G. F. 2003. "Interface management within construction: In particular, building façade.” J. Constr. Eng. Manage. 129(1), 8-15.

Podsakoff, P. M., MacKenzie, S. B., Lee, J-Y., and Podsakoff, N. P. 2003. "Common method bias in behavioral research: a critical review of the literature and recommended remedies." Journal of Applied Psychology. 88(5), 879-903.

Project Management Institute (PMI), 2017. A Guide to the Project Management Body of Knowledge (PMBOK Guide). Sixth edition. (Newton Square).

Puranam, P., Raveendran, M., Knudsen, T. (2012). "Organization design: The epistemic interdependence perspective”. Academy of Management Review, 37(3), 419-440.

Ryall, M.D., and Sampson, R.C. 2009. "Formal contracts in the presence of relational enforcement mechanisms: evidence from technology development projects.” Manage. Sci. 55 (6), 906-925.

Savelsbergh, C.M., Poell, R.F., and van der Heijden, B.I. 2015. "Does team stability mediate the relationship between leadership and team learning? An empirical study among Dutch project teams." Int. J. Proj. Manag. 33, 406-418.

Sharma, S. 1996. Applied multivariate techniques. Wiley, New York, 116-123.

Shen, W., Tang, W., Wang, S., Duffield, C. F., Hui, F., and You, R. 2017. "Enhancing Interface Management in International Engineering-Procurement-Construction Projects." J. Constr. Eng. Manage. 143(9), 04017061.

Shen, W., Choi,B., Lee.S., Tang.W., and Haas,C. 2018a. "How to improve interface management behaviors in epc projects: the roles of formal practices and social norms." J. Manage. Eng. 34(6), 04018032 .

Shen, W., Choi, B., Lee, S., and Tang, W. 2018b. "Effects of Formal Practices and Teamwork on Interface Management Performance in Large-Scale Construction Projects." Construction Research Congress 2018, $356-366$.

Shen, W., Tang, W., Yu, W., Duffield, C.F., Hui, F.K.P., Wei, Y., Fang, J., 2017. “Causes of contractors' claims in international engineering-procurement-construction projects". J. Civ. Eng. Manag. 23, 727-739.

Shokri, S., Ahn, S., Lee, S., Haas, C. T., and Haas, R. C. G. 2015. "Current status of interface management in construction: drivers and effects of systematic interface management." J. Constr. Eng. Manag. 04015070 .

Shokri, S., Haas, C.T. G., Haas, R.C., and Lee, S.H. 2016. "Interface-Management Process for Managing Risks in Complex Capital Projects.” J. Constr. Eng. Manag. 142, 4015069.

Simon, H.A., March, J.G. (1993). Organizations. Cambridge, MA: Blackwell Business

SPSS version 21.0 [Computer software]. IBM, Chicago.

Tang, W., Duffield, C.F., and Young, D.M. 2006. "Partnering mechanism in construction: an empirical study on the Chinese construction industry.” J. Constr. Eng. Manag. 132 (3), 217-229. 
Tang, W., Li, Z., Qiang, M., Wang, S., and Lu, Y. 2013. "Risk management of development in China." Energy. 60, 316-324.

Wang, E. T. G., Tai, J. C. F., and Grover, V. (2013). "Examining the relational benefits of improved interfirm information processing capability in Buyer-Supplier Dyads." MIS Quarterly, 37(1), 149-173.

Williamson, O. E. 1979. "Transaction-cost economics: The governance of contractual relations." J. Law Econ., 22(2), 233-261.

Wood, G., McDermott, P., and Swan, W. (2001). "The ethical benefits of trust-based partnering: The example of the construction industry." Annual Conf. of EBEN-UK Ethics Matters for Business, Nottingham, U.K.

Wren, D. A. 1967. “Interface and interorganizational coordination.” Acad. Manage. J. 10 (1): 69-81.

Zheng, J., Roehrich, J. K., and Lewis, M. A. 2008. “The dynamics of contractual and relational governance: evidence from long-term public-private procurement arrangements.” Journal of Purchasing and Supply Management 14(1), 43-54. 


\section{List of Figure Captions}

715 Fig. 1. Conceptual interface management framework.

716 Fig. 2. Parameter estimates for the structural model. 


\section{University Library}

\section{- M M N E R VA A gateway to Melbourne's research publications}

Minerva Access is the Institutional Repository of The University of Melbourne

Author/s:

Shen, W;Tang, W;Wang, Y;Duffield, CF;Hui, FKP;Zhang, L

Title:

Managing Interfaces in Large-Scale Projects: The Roles of Formal Governance and Partnering

Date:

2021-07-01

Citation:

Shen, W., Tang, W., Wang, Y., Duffield, C. F., Hui, F. K. P. \& Zhang, L. (2021). Managing Interfaces in Large-Scale Projects: The Roles of Formal Governance and Partnering. JOURNAL OF CONSTRUCTION ENGINEERING AND MANAGEMENT, 147 (7), https:// doi.org/10.1061/(ASCE)CO.1943-7862.0002101.

Persistent Link:

http://hdl.handle.net/11343/276976 